\title{
Choosing the appropriate peer-reviewed journal for submission of your manuscript
}

\author{
Martin Caon ${ }^{1}$
}

Published online: 21 September 2018

(c) Australasian College of Physical Scientists and Engineers in Medicine 2018

There are probably many journals to which you could submit a manuscript describing your research [1]. How then does an author determine which journal is the appropriate one for submission of their manuscript?

Sometimes we reject a submitted manuscript without reviewing it because we decide that it falls outside of the medical physics and biomedical engineering areas in which APESM publishes and hence we don't have the expertise to manage the peer-review of the manuscript [2]. That is, the authors of a submitted manuscript have misjudged the sort of content that is likely to be published in APESM. Sometimes authors enquire of the Editor before submitting their manuscript, whether their manuscript would be suitable for APESM. In this case the Editor can be direct with the author and say yes or no.

It can occur that a manuscript that has been accepted for peer-review, proves difficult to assess because one potential reviewer after another declines to review it when invited. This may mean that the Editor has erred by accepting it for review, when in fact it should have been rejected because the editorial expertise to uncover suitable reviewers in the manuscript's content area is lacking. But sometimes you don't know until you try.

The many unsolicited requests that you probably receive from newly established "journals" to submit a manuscript to them may give the impression that manuscript submission is a seller's market (where the seller is the author). However when the Editor's comments are read along with the reviewer reports, the author may be left with the impression that it is a buyer's market (where the journal is the buyer). If your manuscript describes sufficiently novel and sound research and is well written and adjudged likely to attract

Martin Caon

martin.caon@flinders.edu.au

1 College of Nursing and Health Sciences, Flinders University, Adelaide, Australia citations, then believe me, manuscript submission to reputable journals is a seller's market.

In general terms, when deciding where to submit, choose a journal in "good standing". This probably means one sponsored by a member-based scientific society whose members share a common professional and scientific interest (like this journal); one published and supported by an established and reputable commercial publisher (again, like this journal). It certainly means one that peer-reviews the submitted work. The reviewers should be external and be published researchers in the field. See the Author Index Volume 41 at the end of this issue for the list of reviewers that have considered the manuscripts published in, or rejected by APESM in 2018. A journal in good standing has gained its reputation by being well-managed and being operated ethically by a sound editorial staff using sound editorial practices. In this case, the journal and editor will probably be members of Committee on Publishing Ethics (COPE) ${ }^{1}$ as is this journal. A reputable journal will have a long publishing history. In this case the editorial staff will have the experience and expertise to oversee the peer-review process.

Choose a journal that is easily accessible, highly visible, and whose articles are authored by scientists from all over the world and are frequently downloaded and often cited. Since the proliferation of the internet, accessibility means that published articles are posted on the Journal's well-maintained website. It also usually means publishing in an English-language journal. Choose a journal from those whose title is an apt description of the broad subject area of your manuscript. This last piece of advice may not be of much use for authors without a native English-speaking background as the journal title cannot be all encompassing or may be ambiguous.

It may seem strange to recommend submitting to a journal with a high rejection rate, but such a journal is less likely to publish lower quality or flawed work, hence is more likely

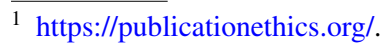


to be consulted by readers seeking authoritative sources. In 2017, APESM rejected $73 \%$ of submissions.

In specific terms, when deciding where to submit, choose a journal that appears often in the reference list of your manuscript, as clearly, it publishes much that is relevant to your current manuscript. Choose a journal that publishes articles that you often read, as again, they are clearly in the area of your interest and expertise. Choose one that your colleagues, you or your co-authors have published in before-they have after all, accepted your work in the past. Publish in a journal that has invited you to review a manuscript for them. Such an invitation usually means that the journal publishes in your area of interest and believes that you are a suitable reviewer for their content. Their belief is based on your published work so in this case the journal has found you rather than the other way around.

Do not submit your manuscript to a journal that promises publication within a suspiciously very short time from submission. Probably do not choose one that has sent an unsolicited email asking for you to submit a manuscript. These journals may be sham rather than scholarly journals. You may be aware of the list of potential predatory publishers and potential predatory scholarly open-access journals that was created by librarian Jeffrey Beall. This list is no longer maintained but an archived version of Beall's list (with some updates) may be found here: https://beallslist.weebly.com/. Meanwhile Cabells Scholarly Analytics (Cabell International) https://www2.cabells.com/, a for-profit organisation that charges for its products, maintains a blacklist of sham journals and also a whitelist of reputable journals.

$\mathrm{Be}$ aware that some journals may charge a fee for publication and that sometimes the fee is justified. You may wish your manuscript to be freely available to anyone and so you could choose an open-access rather than a subscription-based journal. Reputable open access journals that peer review, will charge a fee for publication.

If you have no idea about where to start searching for a suitable journal for a particular manuscript, try using a publisher's journal finder search software such as Springer Nature: Find the right journal (https://journalsuggester.sprin ger.com/). Here you enter the manuscript title and some text from your manuscript, then perhaps select a broad subject area from a dropdown list before "clicking on the search button". Of course the suggested journals are limited to those published by Springer Nature (including BioMed Central), but other publishers such as Elsevier, (https://journalfinder. elsevier.com/) and Wiley (http://wileyeditingservices.com/ en/journal-recommendation/) have similar sites. A journal finding site that is free and is not tied to a particular publisher is JournalGuide (https://www.journalguide.com/). I am pleased to report that for APESM, JournalGuide's website states: "This journal is included in the JournalGuide whitelist of reputable titles".

\section{References}

1. Caon M (2016) There are too many medical physics journals! Australas Phys Eng Sci Med 39:813-816. https://doi.org/10.1007/ s13246-016-0485-3

2. Caon M (2018) Revise before review; reject without review; reject after review: why manuscripts are rejected. Australas Phys Eng Sci Med 419:3-5. https://doi.org/10.1007/s13246-018-0615-1 